\title{
PSYCHOSOCIAL AND PHYSIOLOGICAL RISKS OF SHIFT WORK IN NURSES: A CROSS-SECTIONAL STUDY
}

\author{
Belén Leyva-Vela1', Francisco Jesús Llorente-Cantarero ${ }^{2,3}$, Silvia Henarejos-Alarcón ${ }^{1}$, \\ Alejandro Martínez-Rodríguez ${ }^{4}$ \\ ${ }^{1}$ Vinalopó University Hospital, Elche, Spain \\ 2Department of Physical Education and Sport, Faculty of Education, University of Sevilla, Sevilla, Spain \\ ${ }^{3}$ Maimónides Biomedical Research Institute of Córdoba, Sevilla, Spain \\ ${ }^{4}$ Department of Analytical Chemistry, Nutrition and Food Science, Faculty of Science, University of Alicante, Alicante, Spain
}

\section{SUMMARY}

Objectives: Many jobs are associated with psychological or social risk factors. Knowledge of occupational diseases is essential for adopting rational control measures. The aim was to study and describe frequent social, psychological and physiological risk factors for nurses.

Methods: Psychological and social risks were evaluated in nurses with regular or irregular shifts. In addition, differences between nurses or nursing assistants were studied. The Copenhagen Psychosocial Questionnaire, Eating Attitudes Test, Profile of Mood State, Athens Insomnia Scale, Trait Anxiety Inventory, and Minnesota Leisure Time were administered.

Results: Nursing assistants presented higher levels of body mass index and food restriction than nurses, nevertheless, nurses showed increasing tension in work. In nursing, shift work increases psychosocial risks, insomnia, eating disorders, and trait anxiety.

Conclusions: In conclusion, nurses and nursing assistants in health centres and hospitals show high levels of exposure to psychological and psychosocial risks that are unfavourable to their health.

Key words: nursing workload, sleep disorders, eating disorders, psychology of work, psychosocial work environment

Address for correspondence: A. Martínez-Rodríguez, Department of Analytical Chemistry, Nutrition and Food Science, Faculty of Science, University of Alicante, Alicante, 03690 San Vicente del Raspeig (Alicante), Spain. E-mail: amartinezrodriguez@ua.es

https://doi.org/10.21101/cejph.a4817

\section{INTRODUCTION}

Nowadays, nursing jobs demand a great amount of different physical activities. Physical activity (PA) might be observed from a different point of view. Researchers have generally understood PA as an activity associated with exercise, sport or training (1). However, it is possible to find daily routines or jobs which may present moderate-vigorous activity (2). Ainsworth et al. in 2000 established a new Compendium of PA analysing energy expenditure of many routine tasks and sport practice that may be used in the development of several jobs, for example nursing among others (2). Within nurse tasks, there are some that require a certain effort such as care for elderly or disabled adults, pushing a wheelchair; walking $8 \mathrm{~km}$ per hour; serving food - walking or standing.

Adding to this level of effort (activity), nursing has proven to be a qualified job that present a high susceptibility to occupational stress (3) and burnout (4), because nurses have to cover staffing shortages, adapt to changes in patients' conditions, keep up with technological advances, and also shift work, showing an increase in fatigue when compared with other health positions (5). Many stress factors (working conditions and climate, relations with colleagues, conflict of roles and ambiguity, work-home combination, career development, etc.) of this profession may contribute to job discontent, which could worsen the quality of patient care and increase working time during a shift (6).

Many published studies are focused on psychosocial conditions and emotional experience in the work environment, especially the combination of high psychological demands and workload associated with the risk of developing some diseases (4). Negative emotions are conceived as determinant factors of job dissatisfaction influencing the way employees identify their working environment. It is important to study nurses' mood states because their work condition and their work-family interface could affect their psychological state. Anxiety and disempowerment as well as working long hours are some factors of dissatisfaction among nurses (7).

Nowadays, nursing is a profession where changes of workdays and shift work is present affecting the nurses' physical and psychological health (8). Furthermore, sleep disturbance caused by professional demands contributes to decreases in work efficiency, increases accident rates and diminishes cognitive function caused by sleep deprivation. It is recognized as an important public health and safety issue (9). A recent study showed that sleep deficiencies and circadian disruption have been associated with metabolic deregulation and might contribute to weight gain or onset of obesity and type 2 diabetes due to disorders in the time and amount of food intake and disrupted energy balance (10). 
Scientific evidence has suggested a relationship between being obese and suffering depression (11).

The aim of this study was to study the physiological (body mass index), psychological (trait anxiety, mood state, psychosocial risks, eating disorders), and insomnia problems caused by nursing work in Spain. Levels of anxiety, mood state, insomnia, eating disorders, and psychosocial risks were compared between nursing workforces belonging to the following two groups: nurses versus nursing assistants; and day working employees versus shift working employees.

\section{MATERIALS AND METHODS}

\section{Design and Sample}

A cross-sectional study was conducted in a total of 214 Spanish female nursing workforce (nurses and nursing assistants) from two public Spanish hospitals to evaluate psychological parameters and shift work in nursing. Ethical approval was given by the Ethical Committee of Alicante University in Spain and was performed in accordance with the code of ethics of the World Medical Association (Declaration of Helsinki).

We excluded subjects under psychiatric treatment and pregnant women. The subjects considered for inclusion were nurses with work experience in a hospital for at least 2 years and those that have been working regular shifts (day: 8 a.m. to 3 p.m. or 3 p.m. to 10 p.m.) or irregular shifts (day: 8 a.m. to 8 p.m. and night: 8 p.m. to 8 a.m.) for at least 1 year. Substantial differences between nurses and nursing assistants are based on that nurses have more responsibilities with the patients and medical care related to drugs administration and other protocols applying specific knowledge, increased physical load with less rest time than nursing assistants, affecting the possibility to have enough time to eat adequate meals during job performance.

\section{Measures}

\section{Social and Demographic Questionnaire}

The questionnaire included items covering demographic factors (gender, age, marital status, children living at home) and working conditions (including years of nursing experience and estimated number of night shifts in the last year). The questionnaire also included a question on current shift schedule (day or day and night).

\section{Body Composition}

Total body weight was measured using Tanita BC-418 MA (Tanita Corporation, Arlington Heights, IL) to the nearest 0.1 $\mathrm{kg}$. Standing height was measured using a Seca 202 stadiometer (Seca, Hamburg, Germany) to the nearest $0.1 \mathrm{~cm}$. Body mass index (BMI) "weight/(height $\left.{ }^{2}\right)$ " was evaluated following the methodology of the International Society for the Advancement of Kinanthropometry (ISAK) (12).

\section{Copenhagen Psychosocial Questionnaire}

The Copenhagen Psychosocial Questionnaire (COPSOQ) is a comprehensive questionnaire which includes several psychosocial aspects covered by major occupational health theories adapted and validated to the Spanish population (13). COPSOQ was configured with 6 dimensions (38 items); scoring the answers on a 4-point scale ranging from never to always. The analysis of internal validity and consistency of the questionnaire (Cronbach's alpha) for the 6 measured factors were: psychological demands (0.71); active work and development (0.75); insecurity (0.75); social support and quality of leadership (0.71); dual presence (0.74); high regard (0.73); and total COPSOQ (0.74).

\section{Profile of Mood State}

One of the most commonly used tests is the Profile of Mood States (POMS) questionnaire, which assesses mood changes associated to different stressors. The questionnaire provides a global distress score from 29 items and 5 sub-scales that include tensionanxiety, depression-dejection, anger-hostility, vigour-activity, and fatigue. In this study the abbreviated version of POMS was used (14). This questionnaire includes questions regarding the individual's emotions during the past week, scoring the answers on a 5-point scale ranging from 0 (not at all) to 4 (extremely). Each sub-scale contains different items, the maximal score that can be obtained is different for each particular sub-scale. The analysis of internal validity and consistency of the questionnaire (Cronbach's alpha) for the 5 measured factors and total score were: tension (0.72); depression-dejection (0.78); hostility-anger $(0.80)$; vigouractivity (0.89); fatigue (0.85); and POMS total score (0.84).

\section{Eating Attitudes Test}

The Spanish version (15) of abbreviated Eating Attitudes Test (EAT-26) questionnaire was used in the study. This validated questionnaire obtains information about symptoms and concerns related to eating disorders. This is performed through the sum of 26 items subdivided into 3 scales. The dieting scale evaluates food restriction and obsession for thinness. The bulimia and food preoccupation scale evaluates the use of bulimic/purgative behaviours and thoughts about food. Finally, the oral control scale evaluates food intake self-control and the pressure of the environment to lose weight. The score alerting a risk of developing possible eating disorder is 20 points from a total of 78 . The analysis of internal validity and consistency of the questionnaire (Cronbach's alpha) for the 3 measured factors and total score were: dieting $(0.78)$; bulimia (0.75); oral control (0.73); and EAT-26 total score (0.82).

\section{State and Trait Anxiety Inventory}

Trait sub-scale of Spanish adaptation of the State and Trait Anxiety Inventory (STAI) (16) was measured in this study. This sub-scale questionnaire comprises 20 items and the answer scale ranges from 0 (nothing) to 3 (a lot). The analysis of internal validity and consistency of the questionnaires (Cronbach's alpha) total score was 0.75 .

\section{Athens Insomnia Scale}

The Athens Insomnia Scale (AIS) validated for the Spanishspeaking population (17), is a self-reported psychometric instrument designed to quantify sleep difficulty based on the ICD-10 Classification of Mental and Behavioural Disorders (18). It consists of 8 items and scores, each item from 0 (no problem at all) to 3 (very serious problem). The total score of AIS- 8 therefore ranges from 0 to 24 . A total score equal or greater than 6 suggests inadequate 
sleep (19). The analysis of internal validity and consistency of the questionnaires (Cronbach's alpha) total score was 0.84 .

\section{Minnesota Leisure Time}

For the assessment of PA performed during a nursing job, the Minnesota Leisure Time Physical Activity Questionnaire was used. This questionnaire has been validated for use among Spanish women (20).

\section{Statistical Analysis}

Descriptive analysis was performed in order to assess the different data groups in the sample studied. Data is presented as means \pm SEM. The Kolmogorov-Smirnov test resulted in a normal distribution of the variables. Mann-Whitney, unpaired Student's t-test and chi-square tests were used for statistical analysis. Correlations between variables were assessed by the Pearson's coefficient correlation test. $\mathrm{P}$ value $<0.05$ was considered as statistically significant. Analysis was performed with SPSS 20.0 for Windows (IBM Corporation, Armonk, NY, USA).

\section{RESULTS}

Regarding PA of participants, they affirmed that they did not exercise regularly in their free time. Nevertheless, they declared to have performed the following PA during their work-time: walking (leading healthcare cart, carrying medical supplies), jogging or fast walking (emergency), climbing stairs, cleaning tasks, and specific nursing tasks. In addition, over $70 \%$ of day shifts presented a high activity, but on night shifts, this percentage decreased slightly to $60 \%$.

Psychological, psychosocial and individual characteristics of participants are listed in Tables 1 and 2. When comparing nursing jobs, the nursing assistant group showed higher levels of weight $(p=0.016)$, BMI $(p=0.009)$ and food restriction $(p=0.005)$ than the nurse group (Table 1). In contrast, the nursing assistant group presented lower active work and development $(p=0.033)$, and tension $(p=0.016)$ than the nurse group (Table 1$)$. Comparing day work with shift work, nurses and nursing assistants that had day work exhibited lower active work and development $(p=0.008)$, insecurity $(p=0.003)$ and trait anxiety $(p<0.001)$ than those who worked rotating shifts (Table 1). However, nursing workforce with day work presented greater high regard $(p=0.002)$ than those with shift work. No differences were found in insomnia scores between the two groups (Table 1).

Table 2 shows COPSQ descriptive mean values of the sample by subgroups and their relationship with psychosocial exposure levels that are or are not favourable to health. The prevalence to present greater possibility of eating disorders (EAT-26 Total Score $\geq 20$ points) was $6.5 \%$ in the nursing assistant group, $3.5 \%$ in the nurse group, and $10 \%$ in nurses with shift work. Furthermore,

Table 1. Descriptive of psychological, psychosocial and individual characteristics of nursing workforce $(m e a n \pm S E M)(N=214)$

\begin{tabular}{|c|c|c|c|c|}
\hline Variables & $\begin{array}{l}\text { Nursing assistants } \\
\qquad \mathrm{n}=92\end{array}$ & $\begin{array}{l}\text { Nurses } \\
n=122\end{array}$ & $\begin{array}{c}\text { Day work } \\
n=38\end{array}$ & $\begin{array}{c}\text { Shift work } \\
n=176\end{array}$ \\
\hline Age & $39.04 \pm 1.25$ & $35.64 \pm 0.74$ & $35.37 \pm 1.72$ & $37.48 \pm 0.75$ \\
\hline Weight & $65.42 \pm 1.12$ & $62.08 \pm 0.90^{*}$ & $66.25 \pm 1.75$ & $62.93 \pm 0.78$ \\
\hline Height & $163.96 \pm 0.70$ & $164.93 \pm 0.55$ & $166.74 \pm 1.00$ & $164.03 \pm 0.47$ \\
\hline Body mass index $\left(\mathrm{kg} / \mathrm{m}^{2}\right)$ & $24.37 \pm 0.41$ & $22.78 \pm 0.27^{* *}$ & $23.82 \pm 0.60$ & $23.39 \pm 0.27$ \\
\hline Psychological demands & $14.33 \pm 0.32$ & $14.16 \pm 0.27$ & $13.68 \pm 0.57$ & $14.35 \pm 0.21$ \\
\hline Active work and development & $22.89 \pm 0.58$ & $24.21 \pm 0.31^{*}$ & $21.42 \pm 0.93$ & $24.13 \pm 0.31^{* *}$ \\
\hline Insecurity & $9.02 \pm 0.38$ & $9.38 \pm 0.32$ & $7.68 \pm 0.63$ & $9.56 \pm 0.26^{* *}$ \\
\hline Social support and quality of leadership & $27.72 \pm 0.52$ & $27.08 \pm 0.41$ & $28.32 \pm 0.79$ & $27.15 \pm 0.35$ \\
\hline Dual presence & $7.13 \pm 0.45$ & $6.54 \pm 0.38$ & $6.74 \pm 0.60$ & $6.81 \pm 0.33$ \\
\hline High regard & $11.11 \pm 0.37$ & $10.70 \pm 0.24$ & $11.95 \pm 0.68$ & $10.65 \pm 0.20^{* *}$ \\
\hline Tension & $6.11 \pm 0.36$ & $7.31 \pm 0.33^{*}$ & $6.68 \pm 0.59$ & $6.82 \pm 0.27$ \\
\hline Depression-dejection & $1.93 \pm 0.31$ & $1.66 \pm 0.19$ & $1.16 \pm 0.25$ & $1.91 \pm 0.20$ \\
\hline Hostility-anger & $7.52 \pm 0.51$ & $6.75 \pm 0.40$ & $6.89 \pm 0.69$ & $7.13 \pm 0.36$ \\
\hline Vigor-activity & $10.80 \pm 0.47$ & $10.56 \pm 0.37$ & $11.74 \pm 0.42$ & $10.43 \pm 0.34$ \\
\hline Fatigue & $6.50 \pm 0.47$ & $5.95 \pm 0.37$ & $5.58 \pm 0.65$ & $6.32 \pm 0.33$ \\
\hline POMS total score & $111.26 \pm 1.56$ & $111.11 \pm 1.09$ & $108.58 \pm 1.92$ & $111.74 \pm 1.03$ \\
\hline Food restriction & $5.17 \pm 0.60$ & $3.46 \pm 0.37^{\star *}$ & $3.53 \pm 0.61$ & $4.34 \pm 0.39$ \\
\hline Bulimia & $0.72 \pm 0.17$ & $0.90 \pm 0.13$ & $0.47 \pm 0.13$ & $0.90 \pm 0.12$ \\
\hline Oral control & $1.61 \pm 0.22$ & $1.05 \pm 0.13$ & $1.32 \pm 0.32$ & $1.28 \pm 0.13$ \\
\hline Eating attitudes Test- 26 total score & $7.50 \pm 0.86$ & $5.41 \pm 0.52$ & $5.32 \pm 0.85$ & $6.52 \pm 0.55$ \\
\hline Trait anxiety score of STAI & $24.98 \pm 0.56$ & $25.97 \pm 0.47$ & $22.42 \pm 0.70$ & $26.22 \pm 0.40^{* * *}$ \\
\hline Athens insomnia scale total score & $5.61 \pm 0.44$ & $4.82 \pm 0.34$ & $4.42 \pm 0.64$ & $5.32 \pm 0.30$ \\
\hline
\end{tabular}

SEM - standard error of the mean

${ }^{*} p \leq 0.05,{ }^{* *} p \leq 0.010,{ }^{* * *} p \leq 0.001$ - statistical significance between groups of nurses (nursing assistants vs. nurses) and between groups of work-day (day work vs. shift work) 
those over 36 years of age presented a $10 \%$ possibility to show eating disorders in the future.

In relation to inadequate sleep, shift work showed greater prevalence in both groups: nursing assistants (day work 9\%, shift work $37 \%$ ) and in nurses (day work $2 \%$, shift work $28 \%$ ).

Table 3 shows the results from the multiple linear regression analysis for the nutritional status, age, weight, psychosocial aspects, mood states, symptoms and concerns related to eating disorders, trait anxiety, and insomnia scales. The present study indicates a positive relationship between psychological demands plus insecurity at work, tension, depression-dejection, fatigue, low POMS total score and insomnia. There was a negative correlation between active work and development, social support and quality of leadership besides high regard, and tension, depressiondejection, hostility-anger, low POMS total score, bulimia and oral control. Dual presence showed a significant positive relationship with food restriction, bulimia, eating attitudes Test-26 total score, and high weight, BMI and age.

\section{DISCUSSION}

The present study aimed to investigate physiological, psychological and insomnia problems caused by nursing work in Spain. The lifestyle behaviours of nurses and nursing assistants together with occupational factors make nursing an unhealthy profession. Nurses are more prone to non-communicable diseases, as well as an increased predominance of obesity, inadequate diet or insufficient PA (21). Despite having received as nurses an education relating to health promotion and health behaviours of patients; it seems that this knowledge is not always transferred to themselves. It is necessary for an intervention amongst nurses earlier on in their careers to establish healthy lifestyle behaviours (22).

Nursing assistants presented higher levels of weight and BMI than nurses. These values are among ranges of normal-weight, although, nursing assistants were close to overweight. It may be due to differences in age as a presence of overweight and obesity in those older than 46.8 years has been observed. In addition, those with a $\mathrm{BMI}<25$ have presented more effort to lose weight. On the other hand, shift work, mainly in those on evening or night shifts, has been associated with overweight or obesity (23). The present study did not show differences between day or shift work. This might be surprising considering the prevalence of sedentary habits affirmed by both study groups. However, it may be somewhat influenced by high workload at the hospital. A study proved that hospital nurses walked 4-5 miles during a 12-hour shift although this depended on shifts or number of assigned patients (24).

Despite these positive aspects not everything is good around nursing. The fact that nurses experience elevated physical and psychological demands at work without external motivators like financial benefits (adequate salary), self-content (respect and support from colleagues and superiors), and opportunities like promotion possibilities, security, etc., means that in general they suffer poor quality of life. According to this affirmation, the present study showed a high percentage of psychological demands and insecurity in the Red area of both nursing assistants and nurses, as well as day and shift work, offering a direct reflection on nurses who presented higher levels of tension than nursing assistants and higher insecurity of shift work than day work. Together, these factors may result in depression, fatigue or bad mood. On the other hand, active work and development is a positive factor beforehand, which is more presented in nurses and shift work in this study, along with a raised motivational character but that may turn into an obsession.

However, to the problems previously mentioned, we should add the familial coexistence. Nurses that worked night shifts have experienced negative influences on their lives like reduced family time and problems in resolving family conflicts. Other problems include insufficient time for themselves or home responsibilities (21) and in some cases their husbands disapproved their profession due to the fact that they take home the stress and problems they endure at work (25). On the physical side, a decrease in quality of life was manifested by restless sleep or a poor life style due to a lack of energy, taking medical treatment to be able to do everyday activities, and an incapability to do work.

Finally, all these aspects are translated into stress that results in the onset of anxiety (the most commonly used stress measurement). It has been found that the nursing occupation presents high levels of stress (26). In public hospitals nurses were related to greater levels of occupational stress and job dissatisfaction.

Ghiyasvandian (3) did not find any relation between quality of life or occupational stress and factors like position. Many symptoms have been associated with job strain, such as headaches, sore shoulders and neck, indigestion, loss of efficiency at work, and insomnia, among others (27). Our results suggested that higher levels of anxiety affect insomnia and probability of

Table 2. Descriptive results of psychosocial risk exposure level measures by Copenhagen psychosocial questionnaire $(N=214)$

\begin{tabular}{|c|c|c|c|c|c|c|c|c|c|c|c|c|}
\hline \multirow{2}{*}{$\begin{array}{l}\text { Factor } \\
\text { PREL }\end{array}$} & \multicolumn{3}{|c|}{ Nursing assistant $(n=92)$} & \multicolumn{3}{|c|}{ Nurse $(n=122)$} & \multicolumn{3}{|c|}{ Day work nurses $(n=38)$} & \multicolumn{3}{|c|}{ Shift work nurses $(n=176)$} \\
\hline & $\begin{array}{c}\% \\
\text { Green }\end{array}$ & $\begin{array}{c}\% \\
\text { Yellow }\end{array}$ & $\begin{array}{c}\% \\
\text { Red }\end{array}$ & $\begin{array}{c}\% \\
\text { Green }\end{array}$ & $\begin{array}{c}\% \\
\text { Yellow }\end{array}$ & $\begin{array}{c}\% \\
\text { Red }\end{array}$ & $\begin{array}{c}\% \\
\text { Green }\end{array}$ & $\begin{array}{c}\% \\
\text { Yellow }\end{array}$ & $\begin{array}{c}\% \\
\text { Red }\end{array}$ & $\begin{array}{c}\% \\
\text { Green }\end{array}$ & $\begin{array}{c}\% \\
\text { Yellow }\end{array}$ & $\begin{array}{c}\% \\
\text { Red }\end{array}$ \\
\hline PD & 2.2 & 13.0 & 84.8 & 0.0 & 9.8 & 90.2 & 5.3 & 21.1 & 73.7 & 0.0 & 9.1 & 90.9 \\
\hline AWD & 28.3 & 37.0 & 34.8 & 36.1 & 47.5 & 16.4 & 26.3 & 26.3 & 47.4 & 34.1 & 46.6 & 19.3 \\
\hline INS & 2.2 & 17.4 & 80.4 & 1.6 & 16.4 & 82.0 & 5.3 & 21.1 & 73.7 & 1.1 & 15.9 & 83.0 \\
\hline$S S Q$ & 34.8 & 52.2 & 13.0 & 36.1 & 44.3 & 19.7 & 47.4 & 42.1 & 10.5 & 33.0 & 48.9 & 18.2 \\
\hline DUP & 21.7 & 23.9 & 54.3 & 26.2 & 16.4 & 57.4 & 26.3 & 26.3 & 47.4 & 23.9 & 18.2 & 58.0 \\
\hline HRE & 19.6 & 17.4 & 63.0 & 11.5 & 27.9 & 60.7 & 36.8 & 26.3 & 36.8 & 10.2 & 22.7 & 67.0 \\
\hline
\end{tabular}

PREL - psychosocial risk exposure level: Green - psychosocial exposure level more favourable to health, Yellow - intermediate level of psychosocial exposure, Red worst level of exposure to psychosocial health;

PD - psychological demands, AWD - active work and development, INS - insecurity, SSQ - social support and quality of leadership, DUP - dual presence, HRE - high regard 


\begin{tabular}{|c|c|c|c|c|c|c|c|c|c|c|c|c|c|c|c|c|c|c|c|c|c|c|c|}
\hline & & & & & & & & & & & & & & & & & & & & & & & 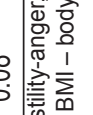 \\
\hline & $\overline{\bar{z}}$ & & & & & & & & & & & & & & & & & & & & 类 & 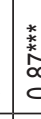 & 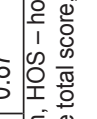 \\
\hline & $\frac{p}{x}$ & & & & & & & & & & & & & & & & & & & E. & $\stackrel{*}{\stackrel{*}{6}}$ & & 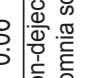 \\
\hline & & & & & & & & & & & & & & & & & & & 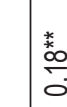 & i & i & & 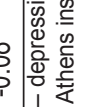 \\
\hline & $\overrightarrow{\mathrm{s}}$ & & & & & & & & & & & & & & & & & & 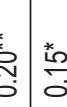 & $\frac{\text { \% }}{0}$ & $\stackrel{m}{\circ}$ & & \\
\hline & b & & & & & & & & & & & & & & & & $\begin{array}{l}\text { 羕 } \\
6 \\
0\end{array}$ & & 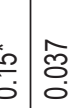 & 응 & ஜ̊. & & \\
\hline & 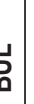 & & & & & & & & & & & & & & & & 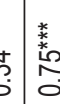 & & $\frac{t}{2} \stackrel{*}{\stackrel{*}{\circ}}$ & $\delta_{0}$ & $\tilde{\delta}$ & & \\
\hline & $\underline{k}$ & & & & & & & & & & & & & & $\begin{array}{l}\text { 絭 } \\
0 \\
0 \\
0\end{array}$ & 歖 & $\begin{array}{l}0 \\
0 \\
0\end{array}$ & & 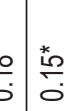 & 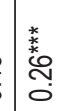 & 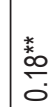 & 桲 & 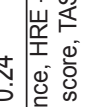 \\
\hline & & & & & & & & & & & & & & c̊ & $\vec{b}$ & $\mid \bar{c}$ & 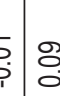 & & $=\frac{\text { s. }}{5}$ & o & $\begin{array}{l}8 \\
0 \\
0\end{array}$ & & 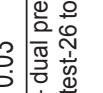 \\
\hline & $\underline{\mathbf{t}}$ & & & & & & & & & & & & 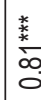 & $\bar{E}$ & $=\frac{*}{50}$ & c & 菅 & $\stackrel{N}{*}^{*}$ & 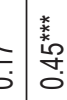 & $\underset{0}{\simeq}$ & ஜூ & & $\frac{a}{2}$ \\
\hline & & & & & & & & & & & & 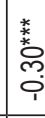 & *o & o & $\begin{array}{l}\vec{b} \\
\dot{b}\end{array}$ & 美 & 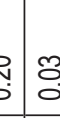 & co & $\begin{array}{l}3 \\
\dot{B}\end{array}$ & $\begin{array}{l}\infty \\
i \\
i\end{array}$ & o & & \\
\hline & $?$ & & & & & & & & & & ס̊. & 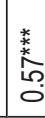 & 嘉 & ¿ & $\stackrel{m}{a}$ & 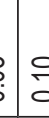 & $\frac{5}{0}$ & $\frac{m}{0}$ & 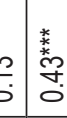 & $\approx$ & o. & & 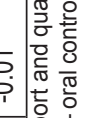 \\
\hline & 岇 & & & & & & & & & 类 & 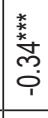 & 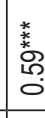 & $\frac{x_{0}^{*}}{\infty}$ & 莡 & 家 & $a$ & 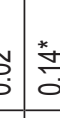 & $\stackrel{*}{\stackrel{0}{0}}$ & $\frac{1}{5}$ & $\stackrel{0}{0}$ & $\hat{0}$ & & 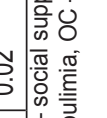 \\
\hline & İ & & & & & & & & 蒌 & 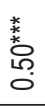 & 竞 & $\begin{array}{l}\text { 糍 } \\
\text { 品 }\end{array}$ & $\begin{array}{l}\text { i } \\
0 \\
0 \\
0 \\
0\end{array}$ & ह & $\stackrel{9}{b}$ & $\mid \begin{array}{c}c \\
c \\
c\end{array}$ & $\begin{array}{l}5 \\
\end{array}$ & 惫 & 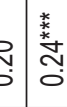 & 응 & 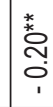 & & 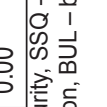 \\
\hline & 崖 & & & & & & & | & 产 & 素 & $\begin{array}{l}\text { 絭 } \\
\text { ¿ } \\
\end{array}$ & 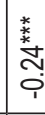 & 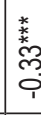 & $\S$ & 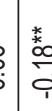 & 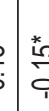 & $\frac{2}{1}$ & O & יִ & 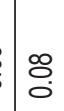 & $\stackrel{*}{\stackrel{*}{\sigma}}$ & & 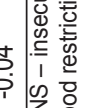 \\
\hline & 3 & & & & & $\stackrel{*}{*}$ & & 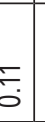 & $\begin{array}{l}0 \\
0 \\
0\end{array}$ & ô. & ¿̊. & $\stackrel{\infty}{0}$ & $\stackrel{\infty}{0}$ & $\stackrel{*}{\Sigma}$ & $\stackrel{*}{*}$ & a & $\stackrel{s}{s}$ & $\frac{m}{c}$ & $\frac{2}{1} \frac{0}{0}$ & 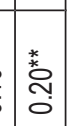 & $\stackrel{*}{\check{O}}$ & & \\
\hline & 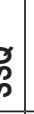 & & & & \llcorner & $\frac{7}{0}$ & & 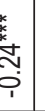 & . & 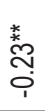 & 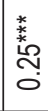 & 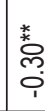 & 辛 & ą & 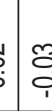 & a & $\begin{array}{l}8 \\
0 \\
0\end{array}$ & Oे & 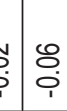 & $\stackrel{*}{\stackrel{*}{\circ}}$ & 응 & & \\
\hline & $?$ & & & 晜 & 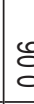 & $\stackrel{*}{*}$ & & : & 蒙 & $\stackrel{m}{\circ}$ & 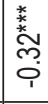 & 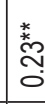 & 兹 & co & b & S: & $\begin{array}{ll}= & 8 \\
1 & 0 \\
1\end{array}$ & 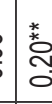 & பّ & 응 & $\stackrel{\overbrace{}}{i}$ & z & \\
\hline & 资 & & ర్ & 苋 & ¿ & 悉 & & 8 & $\begin{array}{l}0 \\
0 \\
0 \\
\end{array}$ & ¿ & $\begin{array}{l}\text { 商 } \\
\text { o }\end{array}$ & 产 & $\frac{*}{40}$ & $\stackrel{\infty}{c}$ & 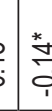 & $\stackrel{c}{c}$ & $\begin{array}{l}8 \\
:\end{array}$ & $\stackrel{m}{\circ}$ & $\begin{array}{l}\stackrel{0}{\circ} \\
\end{array}$ & $\frac{0}{9}$ & : & * & 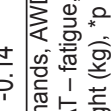 \\
\hline & & 5 & 丞 & 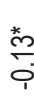 & વૃ & t & & הֶ. & 羙 & 类 & ث. & 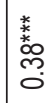 & 类 & ç & 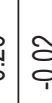 & $\mid \begin{array}{c}5 \\
\vdots \\
\vdots\end{array}$ & 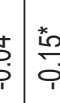 & 응 & $\begin{array}{c}2 \\
\vdots\end{array}$ & $\frac{O}{9}$ & ô. & & ז. \\
\hline & & & $\underline{\mathscr{2}}$ & & 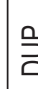 & & W & $\vec{H}$ & 岀 & $\begin{array}{l}\text { 오 } \\
\text { 우에 }\end{array}$ & $\stackrel{0}{>}$ & 悹 & & 品 & $\frac{\mathrm{g}}{\mathrm{m}}$ & $\check{c}$ & 了孚 & $\stackrel{Q}{\mathbb{Z}}$ & ? & $\sum_{\overline{0}}$ & 岁 & 訔 & \\
\hline
\end{tabular}


eating disorders. In this sense, insomnia problems, at the same time, have been related with negative factors of mood state, as it increases depression, hostility and fatigue and decreases vigour.

Depression is also a major public health problem globally and will be ranked the second most common disease in a few years. Actually, in the general population the incidence of depression was over $16 \%$.

Nurses experience interruption in the timing between endogenous circadian rhythms and their atypical sleep-wake schedule. The circadian rhythms direct sleep timing and alertness, and chronic circadian misalignment can derive from sleep and performance complaints but also present an association between night work and elevated health risks (cardiovascular diseases, metabolic syndrome, cancer types, altered autonomous nervous system, etc.) (28).

Some studies (19) show that night shifts increase the incidence of serious health problems (varicose veins, appetite disturbance and sleep disorders) compared to day shifts. It is thought that a long-term adaptation to night shifts is extremely restricted or even inevitable. In this sense, nurses present severe sleep disturbances (29).

Other studies (30) supported an association between decreased sleep duration and increasing BMI. In Spain, it has been proven that sleeping for 9 or more hours had a lower incidence of obesity than those sleeping 6 or fewer hours. More awareness is needed for female nurses who work long duration shift work, as heightened duration of shift work has been associated with higher risk of overweight/obesity in shift-working nurses (23). The availability of unhealthy foods and high cost of healthy foods in the hospitals' cafeterias were associated with unhealthy eating habits by the nurses in this study and may be a possible factor contributing to the problem of overweight and obesity (21). In this context, nurses that worked at night had diet and exercise habits that produced sleep, and they also faced changes in eating habits and food selection. Also, a recent study proved that eating habits have been correlated with work stress and suggest that this relationship could lead to obesity and eating disorders (31).

Regarding the limitations of this study, one important limitation was that its data are based on subjective evaluations. For this reason, further research lines could implement the objective assessment of physical and psychological overload of healthcare services using new technologies such as heart rate variability for reporting data.

\section{CONCLUSIONS}

In conclusion, the consequences of the shift work system in Spanish nursing affected physical and psychological factors, such as eating behaviours, anxiety and mood state. Furthermore, age and weight are two parameters to be considered to determine negative influences related with psycho-physiological aspects studied.

\section{Conflict of Interests}

None declared

\section{REFERENCES}

1. Palacios G, Pedrero-Chamizo R, Palacios N, Maroto-Sánchez B, Aznar S, González-Gross M; EXERNET Study Group. Biomarkers of physical activity and exercise. Nutr Hosp. 2015 Feb 26;31 Suppl 3:237-44.

2. Ainsworth BE, Haskell WL, Herrmann SD, Meckes N, Bassett DR Jr, Tudor-Locke C, et al. 2011 Compendium of Physical Activities: a second update of codes and MET values. Med Sci Sports Exerc. 2011;43(8):157581.

3. Ghiyasvandian S, Adera Gebra A. Coping work strategies and job satisfaction among Iranian nurses. Iran Red Crescent Med J. 2014;16(6):e17779. doi: 10.5812/ircmj.17779.

4. He S, Chen Y, Zhan J, Wu J, Opler M. Job Burnout, mood state, and cardiovascular variable changes of doctors and nurses in a children's hospital in China. ISRN Nurs. 2014 Mar 9;2014:386719. doi: 10.1155/2014/386719.

5. Khamisa N, Peltzer K, Oldenburg, B. Burnout in relation to specific contributing factors and health outcomes among nurses: a systematic review. Int J Environ Res Public Health. 2013;10(6):2214-40.

6. Adib-Hajbaghery M, Khamechian M, Alavi NM. Nurses' perception of occupational stress and its influencing factors: A qualitative study. Iran J Nurs Midwifery Res. 2012 Jul;17(5):352-9.

7. Jafaraghaee F, Mehrdad N, Parvizy S. Influencing factors on professional commitment in Iranian nurses: A qualitative study. Iran J Nurs Midwifery Res. 2014;19(3):301-8.

8. Faseleh Jahromi M, Moattari M, Sharif F. Novice nurses' perception of working night shifts: a qualitative study. J Caring Sci. 2013; 2(3):169-76.

9. McCoy JG, Strecker RE. The cognitive cost of sleep lost. Neurobiol Learn Mem. 2011 Nov;96(4):564-82.

10. Depner CM, Stothard ER, Wright KP Jr. Metabolic consequences of sleep and circadian disorders. Curr Diab Rep. 2014 Jul;14(7):507. doi: 10.1007/s11892-014-0507-z.

11. Pan A, Sun Q, Czernichow S, Kivimaki M, Okereke OI, Lucas M et al. Bidirectional association between depression and obesity in middle-aged and older women. Int J Obes (Lond). 2012;36(4):595-602.

12. Cabañas Armesilla MD, Esparza Ros F. Compendium of kinanthropometry. Madrid: CTO; 2009. (In Spanish.)

13. Moncada S, Llorens C, Navarro A, Kristensen TS. ISTAS21: the Spanish version of the Copenhagen psychosocial questionnaire (COPSOQ). Arch Prev Riesgos Labor. 2005; 8(1):18-29.

14. Perczek R, Carver CS, Price AA, Pozo-Kaderman C. Coping, mood, and aspects of personality in Spanish translation and evidence of convergence with English versions. J Pers Assess. 2000;74(1):63-87.

15. Rivas T, Bersabé R, Jiménez M, Berrocal C. The Eating Attitudes Test (EAT-26): reliability and validity in Spanish female samples. Span J Psychol. 2010;13(2):1044-56.

16. Spielberger CD, Gorsuch RL, Lushene RE. STAI, manual for the StateTrait Anxiety Inventory. Madrid: TEA; 1982.

17. Gomez-Benito J, Ruiz C, Guilera G. A Spanish version of the Athens Insomnia Scale. Qual Life Res. 2011;20(6):931-7.

18. Hajak G, Petukhova M, Lakoma MD, Coulouvrat C, Roth T, Sampson NA, et al. Days-out-of-role associated with insomnia and comorbid conditions in the America Insomnia Survey. Biol Psychiatry. 2011;70(11):1063-73.

19. Kousloglou S, Mouzas O, Bonotis K, Roupa Z, Vasilopoulos A, Angelopoulos N. Insomnia and burnout in Greek Nurses. Hippokratia. 2014;18(2):150-5.

20. Ruiz Comellas A, Pera G, Baena Díez JM, Mundet Tudurí X, Alzamora Sas T, Elosua R, et al. Validation of a Spanish Short Version of the Minnesota Leisure Time Physical Activity Questionnaire (VREM). Rev Esp Salud Publica. 2012 Oct;86(5):495-508. (In Spanish.)

21. Phiri LP, Draper CE, Lambert EV, Kolbe-Alexander TL. Nurses' lifestyle behaviours, health priorities and barriers to living a healthy lifestyle: a qualitative descriptive study. BMC Nurs. 2014;13(1):38. doi: 10.1186/ s12912-014-0038-6.

22. Blake $H$, Harrison $C$. Health behaviours and attitudes towards being role models. Br J Nurs. 2013 Jan 24-Feb 13;22(2):86-94.

23. Kim MJ, Son KH, Park HY, Choi DJ, Yoon CH, Lee HY, et al. Association between shift work and obesity among female nurses: Korean Nurses' Survey. BMC Public Health. 2013 Dec 20;13:1204. doi: 10.1186/14712458-13-1204.

24. Welton JM, Decker M, Adam J, Zone-Smith L. How far do nurses walk? Medsurg Nurs. 2006;15(4):213-6.

25. Nasrabadi AN, Seif H, Latifi M, Rasoolzadeh N, Emami A. Night shift work experiences among Iranian nurses: a qualitative study. Int Nurs Rev. 2009;56(4):498-503. 
26. Gholamzadeh S, Sharif F, Rad FD. Sources of occupational stress and coping strategies among nurses who work in Admission and Emergency Departments of Hospitals related to Shiraz University of Medical Sciences. Iran J Nurs Midwifery Res. 2011;16(1):41-6.

27. Teles MA, Barbosa MR, Vargas AM, Gomes VE, Ferreira EF, Martins AM, et al. Psychosocial work conditions and quality of life among primary health care employees: a cross sectional study. Health Qual Life Outcomes. 2014 May 15;12:72. doi: 10.1186/1477-7525-12-72.

28. Boudreau P, Yeh WH, Dumont GA, Boivin DB. Circadian variation of heart rate variability across sleep stages. Sleep. 2013; 36(12):1919-28.

29. Luyster FS, Strollo PJ, Zee PC, Walsh JK; Boards of Directors of the American Academy of Sleep Medicine and the Sleep Research Society. Sleep: a health imperative. Sleep. 2012 Jun 1;35(6):727-34.
30. McAllister EJ, Dhurandhar NV, Keith SW, Aronne LJ, Barger J, Baskin $\mathrm{M}$, et al. Ten putative contributors to the obesity epidemic. Crit Rev Food Sci Nutr. 2009;49(10):868-913.

31. Potocka A, Mościcka A. Occupational stress, coping styles and eating habits among Polish employees. Med Pr. 2011;62(4):377-88. (In Polish.)

Received April 28, 2016 Accepted in revised form June 15, 2017 